\title{
The Role of Growth Hormone in Adaptation to Massive Small Intestinal Resection in Rats
}

\author{
MICHAEL DURANT, SHARRON E. GARGOSKY, K. ANDERS DAHLSTROM, RIXUN FANG, \\ BARRY H. HELLMAN, JR., AND RICARDO O. CASTILLO \\ Department of Pediatrics [M.D., S.E.G., R.F., R.O.C.], Department of Pathology [B.H.H.], and the \\ Digestive Disease Center [R.O.C.], Stanford University School of Medicine, Stanford, CA, U.S.A.; and \\ Department of Pediatrics, Huddinge Hospital, Karolinska Institute, Stockholm, Sweden [K.A.D.]
}

\begin{abstract}
ABST
The residual small bowel undergoes profound adaptive alter-
ations after surgical resection. GH is considered to have a role in
regulation of these adaptive changes, but its precise role is
unknown. We investigated the role of GH by studying the
response to intestinal resection in rats with isolated GH defi-
ciency. Spontaneous dwarf rats, a strain of rats with congenital
isolated GH deficiency, underwent $60 \%$ resection of the small
intestine and parameters of the response of the intestinal remnant
were compared with age-matched GH-deficient rats undergoing
transection, GH-normal rats undergoing $60 \%$ resection, and non-
manipulated GH-normal rats. Deficiency of GH did not inhibit
hyperplasia of the mucosal mass of the intestinal remnant, indi-
cating that GH is not required for regulation of this aspect of the
adaptive response. However, GH deficiency resulted in lack of
accumulation of mucosal protein, including lack of accumulation
of digestive hydrolases. In addition, GH deficiency resulted in
\end{abstract}
Surgical resection of the small intestine provokes a profound adaptive response in the intestinal remnant characterized by dramatic hyperplasia of the mucosal epithelium and enhanced segmental absorption of nutrients (1-4). These changes result in increased functional capacity of the residual intestine.

Multiple lines of evidence suggest GH may be essential for the marked increase in intestinal growth seen in adaptation to surgical resection. Our group has shown that GH administration is required for normalization of intestinal growth in rats hypophysectomized in early infancy (5). Receptors for $\mathrm{GH}$ have been identified on crypt and villus epithelial cells of the small intestine (6). Small bowel growth has been shown to be enhanced in transgenic mice overexpressing GH (7). Finally, $\mathrm{GH}$ is the major regulator of IGF-I, administration of which

Received February 2, 2000; accepted June 27, 2000

Correspondence: Ricardo O. Castillo, M.D., Department of Pediatrics, Division of Gastroenterology and Hepatology, Stanford University Medical Center, Stanford, CA 94305-5119, U.S.A.

Supported in part by National Institutes of Health grant HD 27366 and grants from the Throne-Holst Foundation, the Swedish Medical Research Council, the Swedish Medical Association, Crown Princess Lovisas Fund, the Karolinska Institute, and Sandoz Nutritionals. alterations in processing of digestive hydrolases of the distal intestine, indicating that $\mathrm{GH}$ may have region-specific effects on small intestinal function. We conclude that $\mathrm{GH}$ is required for the normal expression of specific components of the adaptive response to massive small intestinal resection, but not for all aspects. The aspects that require GH appear to involve protein synthesis and processing. (Pediatr Res 49: 189-196, 2001)

\section{Abbreviations:}
SDR, spontaneous dwarf rats
dr, adult GH deficient rats undergoing intestinal resection
ds, adult GH deficient rats undergoing intestinal transection
dc, adult GH deficient rats not surgically manipulated
Dr, adult GH normal rats undergoing intestinal resection
Dc, adult GH normal rats not surgically manipulated
AOP, aminooligopeptidase

has been shown to result in enhanced intestinal adaptation after resection $(8,9)$. Few studies have been performed to investigate the role of $\mathrm{GH}$ in adaptation of the residual small bowel after surgical resection in which exogenous human recombinant $\mathrm{GH}$ was administered to $\mathrm{GH}$-sufficient rats after small bowel resection. However, contradictory results were obtained, rendering the role of $\mathrm{GH}$ in this setting unclear (10-12).

To clarify the specific role of $\mathrm{GH}$ in regulation of adaptation of the small intestine to surgical resection, we studied a unique strain of Sprague Dawley rat, the SDR. The dwarfism results from an autosomal recessive point mutation in the $\mathrm{GH}$ gene that causes abnormal splicing and a one base deletion in the GH mRNA resulting in markedly reduced levels of GH message. As the small amounts of $\mathrm{GH}$ mRNA are nontranslatable, there is complete absence of $\mathrm{GH}$ protein (13). No GH is detectable in the pituitary of SDR rats when analyzed by PAGE, immunoblot analysis, RIA, or immunocytochemistry. However, the deficiency of $\mathrm{GH}$ is isolated as no effect on prolactin, ACTH, TSH, or LH production has been detected (14). This model offers the opportunity for specific investigation of $\mathrm{GH}$ and $\mathrm{GH}-d e p e n d e n t$ processes without methodolog- 
ical complications introduced by use of hypophysectomy or administration of exogenous GH. Using this model, we have examined the role of $\mathrm{GH}$ or processes dependent upon or regulated by $\mathrm{GH}$ in intestinal adaptation to massive small bowel resection. We have previously used this model for investigation of the role of $\mathrm{GH}$ in regulation of postnatal intestinal maturation (15).

\section{MATERIALS AND METHODS}

Chemicals and reagents. Sucrose, lactose, glucose oxidase (type X), horseradish peroxidase (type VI), p-hydroxybenzoic acid, aminoantipyrine, leucyl-beta-napthylamide, phenylmethylsulfonylflouride, EDTA, and p-hydroxymercuribenzoate were purchased from Sigma Chemical Co. (St. Louis, MO, U.S.A.). Hoechst H-33258 was obtained from Calbiochem (San Diego, CA, U.S.A.). BioRad reagent for protein assay was purchased from BioRad (Richmond, CA, U.S.A.).

Peptides. Recombinant human IGF-1 was obtained from Bachen (Torrance, CA, USA). Recombinant, nonglycosylated IGFBP-3 from Escherichia coli was a generous gift from Celtrix (Santa Clara, CA, U.S.A.). Peptides were iodinated using a modification of the chloramine $\mathrm{T}$ method (16) to specific activities of $350-500 \mathrm{mCi} / \mathrm{mg}$ for IGF-I. Polyclonal antiserum for IGF-I was generously provided by the hormone distribution program of the National Institute of Arthritis, Digestive Diseases and Kidney Diseases (NIADDK) and was originally developed by Drs. J.J. VanWyk and L.E. Underwood (17).

Animals. Control animals were the offspring of pregnant dams of the Sprague Dawley strain purchased from Simonsen Laboratories (Gilroy, CA, U.S.A.). The strain of SDR was generously provided by Dr. S. Okuma (Morishita Pharmaceutical Co., Ltd., Shiga, Japan). These rats carry an autosomal recessive mutation in the GH gene, represented by dr. Their expression of pituitary GH mRNA is only $3-6 \%$ that of control animals, due to an aberrant splice site in the mRNA. Furthermore, this truncated mRNA is not translated into the mature protein due to premature translational termination, such that no GH peptide can be measured in the anterior pituitary gland of SDR $(13,14)$. Unlike other GH-deficient dwarf rat strains available, these rats are unique because they lack only $\mathrm{GH}$ and are otherwise pituitary-sufficient.

All animals were housed in the facilities of the Department of Laboratory Animal Medicine of the Stanford University Medical Center. The animals were maintained at $21 \pm 1^{\circ} \mathrm{C}$ and had a 12-h light, 12-h dark cycle, with lights on at $0700 \mathrm{~h}$. Standard food and water were available ad libitum. The protocols for animal use were approved by the Department of Laboratory Animal Medicine, Stanford University.

Intestinal resection. Adult GH-deficient rats, designated dr, were taken at approximately 3 mo of age and were given clear liquids only for $24 \mathrm{~h}$ before intestinal resection. At the time of operation they were anesthetized with an intramuscular injection of $40 \mathrm{mg} / \mathrm{kg}$ ketamine. Once sedated, the animals received an i.p. injection of $3 \mathrm{mg} / \mathrm{kg}$ Rompun. The abdomen was shaved and then cleansed with povidone-iodine and isopropyl alcohol. Midline laparotomy was followed by evisceration and mea- surement of the small intestine from the ligament of Treitz to the ileocecal valve by placing a measured suture along the antimesenteric border of the gently stretched bowel. The bowel was divided $5 \mathrm{~cm}$ from the ligament of Treitz and $60 \%$ of the measured length of small bowel was then resected. Primary end-to-end anastomosis was accomplished with interrupted 9-0 nylon suture. The abdominal wall was closed with 7-0 polypropylene suture in a running two-layer fashion. At completion of the operation, the animals received i.p. injections of $100 \mathrm{mg} / \mathrm{kg}$ Ampicllin and $5 \mathrm{mg} / \mathrm{kg}$ Kanamycin, and a s.c. injection of 1.1 $\mathrm{mg} / \mathrm{kg}$ Flunixin. The animals were returned to a warm cage until fully recovered. Once fully awake, they were allowed $a d$ libitum oral rehydration solution with glucose and electrolytes only, for the first $24 \mathrm{~h}$ after surgery. Beginning on the second postoperative day, the rats were placed in individual cages and given rat chow and water ad libitum. Daily chow intake and body weight were measured. Two additional GH-deficient groups of rats were studied, one group that underwent intestinal transection without resection (ds), and one group that was not surgically manipulated (de). Control GH-sufficient animals of the same age, designated Dr, similarly underwent intestinal resection by the identical techniques described above. A control group consisting of nonsurgically manipulated GHsufficient animals (Dc) was also studied.

Analysis of intestinal tissues. Animals were killed by cervical dislocation on postoperative $\mathrm{d} 21$. The residual small intestine from the ligament of Treitz to the ileocecal valve was removed and flushed with cold isotonic saline. Pre- and postanastomotic intestinal lengths were measured. The intestinal segments were then weighed and stored at $-80^{\circ} \mathrm{C}$ for subsequent analysis. In nonresected animals, sections of small intestine corresponding to those in resected animals were collected for analysis. Before freezing, small sections were placed in formalin for microscopic analysis. At the time of analysis, whole intestinal samples were homogenized in 10 vol buffer (10 mM sodium phosphate and $5 \mathrm{mM}$ Tris- $\mathrm{HCl}, \mathrm{pH}$ 6.0) containing the protease inhibitors $1 \mathrm{mM}$ phenylmethylsulfonylfluoride and $0.1 \mathrm{mM}$ p-hydroxymercuribenzoate. Activities of lactase-phlorizin hydrolase, and sucrase-isomaltase were determined from homogenates of whole intestine by the method of Dahlqvist (18), as modified by Tsuboi (19). Lactose was used as substrate for brush border lactase. The activity of AOP, the major peptidase of the brush border membrane, was measured using $0.17 \mathrm{mM}$ leucyl- $\beta$-naphthylamide as substrate, as previously described (20). Protein was determined by the BioRad assay, using BSA as the standard (21). DNA content was determined by the method of Labarca and Paigen (22). Enzyme activity units (U) were defined as micromoles of substrate hydrolyzed per minute at $37^{\circ} \mathrm{C}$, and specific activities were expressed as milliunits of enzyme activity per milligram protein.

Tissues for histology were embedded in paraffin, sectioned along the longitudinal axes, and stained with hematoxylin and eosin. Villus height was determined under blinded conditions.

Immunoprecipitation and gel electrophoresis. The particulate and brush border membrane fractions were solubilized by sonication in PBS containing 1\% Triton X-100 and the protease inhibitor mixture and were centrifuged at $100,000 \times g$ for 
30 min. Lactase, sucrase, and AOP were immunoprecipitated from the supernatant using monospecific, polyclonal antibodies as previously described $(19,23-25)$. The immune pellets were washed three times in $62.5 \mathrm{mM}$ Tris, $\mathrm{pH} 6.8$, resuspended in $62.5 \mathrm{mM}$ Tris, pH 6.8, 2\% SDS, $10 \%$ glycerol, 5\% 2-mercaptoethanol, and heated at $95^{\circ} \mathrm{C}$ for $3 \mathrm{~min}$. SDS-PAGE was performed in $7.0 \%$ separating gels according to the method of Laemmli (26). The gels were stained with Coomassie blue.

IGF measurement. Sera from each animal $(25-50 \mu \mathrm{L})$ were diluted to $0.5 \mathrm{~mL}$ in $1.0 \%(\mathrm{wt} / \mathrm{vol})$ formic acid and subjected to size-exclusion chromatography through a G50 Sephadex column (Pharmacia, Piscataway, NJ, U.S.A.) in $1.0 \%(\mathrm{wt} / \mathrm{vol})$ formic acid. The IGF were in the protein fraction eluted between 50 and $85 \mathrm{~mL}$ and were collected in siliconized glass tubes containing $1.0 \mathrm{~mL}$ of $1.0 \%(\mathrm{wt} / \mathrm{vol})$ BSA. Following lyophilization, samples were reconstituted to $1.0 \mathrm{~mL}$ in 10 $\mathrm{mmol} \mathrm{HCl} / \mathrm{L}$, before storage at $-20^{\circ} \mathrm{C}$. IGF-I was measured by RIA, as previously described (16). The minimal detectable concentrations were $0.1 \mathrm{mg} / \mathrm{L}$ for IGF-I. The interassay coefficients of variation were $11 \%$ and $12 \%$ for the IGF-I assays.

Statistics. All data were analyzed using InStat, a statistical software package provided by GraphPad Software (San Diego, CA, U.S.A.). All results are presented as the mean \pm SE. Groups were compared using ANOVA.

\section{RESULTS}

The mortality rate for the intestinal resection in the GHsufficient animal was $25 \%$ (eight animals underwent resection and six survived). The mortality rate for the GH-deficient animals undergoing resection or transection was $36 \%$ in that 14 animals underwent surgery and 9 survived. Dwarf rats required only $50 \%$ of the anesthetic dose required by GH-sufficient animals per body weight, most likely reflecting their altered physiologic state.

Somatic growth and dietary intake. As expected, the growth of the GH-sufficient (Dr) animals exceeds that of their GHdeficient (dr) counterparts before surgery. As shown in Figure 1, Dr animals are gaining approximately $1.65 \mathrm{~g} / \mathrm{d}$ compared with the dr animals' growth of $1.0 \mathrm{~g} / \mathrm{d}$. This is consistent with previously published data (27). Following resection, there is a period of approximately $5-7 \mathrm{~d}$ during which time the body weight of Dr animals decreases before returning to preoperative levels. At this point, $\mathbf{D r}$ animals begin to gain weight rapidly. In contrast, $\mathbf{d r}$ animals do not regain their preoperative weight even by $21 \mathrm{~d}$ after surgery (Fig. 1). The postoperative growth curve for this group of animals is essentially flat. Despite this, $\mathbf{d r}$ animals remained active and well groomed.

The dietary intake data are given in Table 1. No significant differences were noted in dietary intake among the four groups of animals. No differences in intake were noted between GHdeficient animals that underwent intestinal transection (ds) and those that were not surgically manipulated (dc). These data were therefore pooled and given under $\mathbf{d c}$.

Parameters of intestinal growth. On the 21 st postoperative day, resected animals were killed and the pre- and postanastomotic intestinal remnants were weighed, measured, and stored frozen for subsequent analysis. At analysis, no differences in

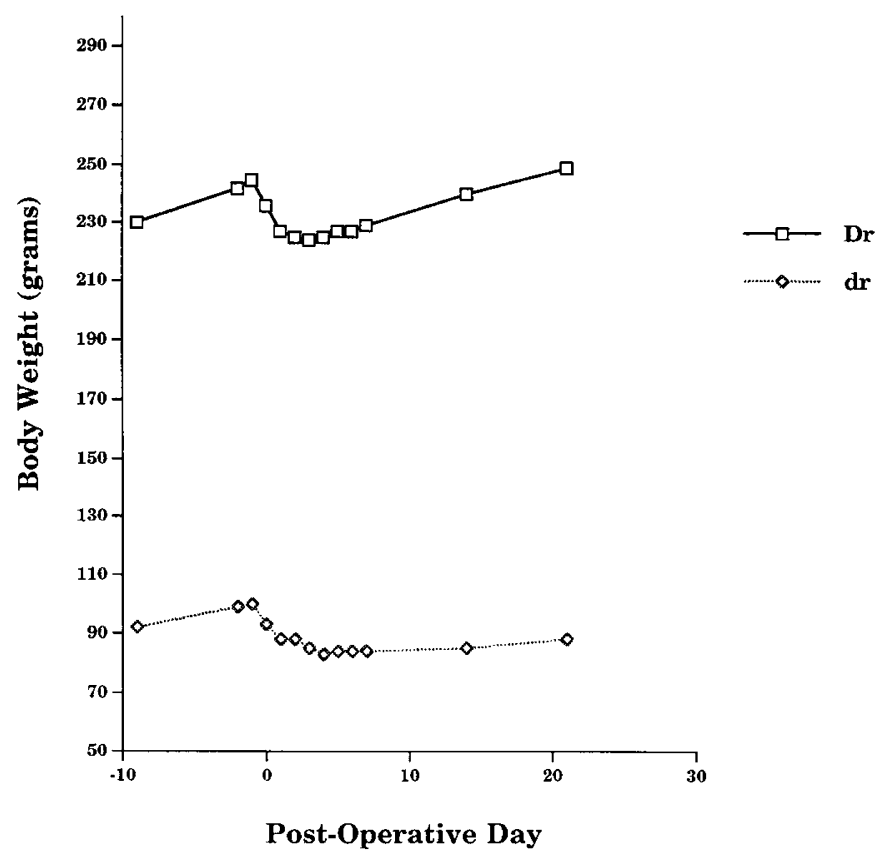

Figure 1. Weight curves of a representative GH-sufficient rat (Dr) and a GH deficient rat (dr) undergoing $60 \%$ resection of the small intestine on postoperative $\mathrm{d} 0$.

Table 1. Measurement of dietary intake

\begin{tabular}{ccc}
\hline $\begin{array}{c}\text { Animal } \\
\text { group }\end{array}$ & $n$ & $\begin{array}{c}\text { Intake } \\
(\mathrm{gm} / \mathrm{kg} / \mathrm{d})\end{array}$ \\
\hline Dc & 6 & $88.9 \pm 2.8$ \\
Dr & 6 & $76.2 \pm 3.5$ \\
dr & 6 & $86.8 \pm 2.2$ \\
dc* $^{*}$ & 6 & $81.5 \pm 5.0$ \\
\hline
\end{tabular}

Data presented as mean \pm SEM. No significant differences in intake were found between animal groups by ANOVA.

* GH-deficient animals undergoing no surgical manipulation $(\mathrm{n}=3)$. $\mathrm{GH}-$ deficient animals with intestinal transection and reanastomosis $(\mathrm{n}=3)$.

results were found between the $\mathbf{d c}$ and $\mathbf{d s}$ groups, hence the data from these two animal groups were pooled and given as dc.

The parameters of the preanastomotic intestinal segments are given in Table 2. In GH-sufficient animals, the preanastomotic segments of animals that underwent intestinal resection showed a two- to threefold increase in weight/length, DNA/ centimeter, and protein content/centimeter, thus exhibiting the adaptive growth expected after resection (Dc versus $\mathbf{D r}$ ). In dr, significant increases in intestinal $\mathrm{wt} /$ length and DNA/ $\mathrm{cm}$ were also observed. Increases in protein content/centimeter were also noted but these did not achieve statistical significance (dr versus dc). The results of the postanastomotic segment are given in Table 3. In the postanastomotic remnant of GHsufficient animals, significant increases were observed in weight for length, DNA/centimeter, and protein/centimeter. In contrast, the postanastomotic segments of GH-deficient animals showed no increases in weight/length or protein/ centimeter, whereas DNA/centimeter was significantly elevated.

The results of the histologic measurements performed in this study are given in Figure 2. In GH-sufficient animals (Dr), 
Table 3. Parameters of response of the postanastomotic intestinal segment

\begin{tabular}{|c|c|c|c|c|c|c|c|}
\hline $\begin{array}{l}\text { Animal } \\
\text { group }\end{array}$ & $n$ & $\begin{array}{l}\text { Weight/length } \\
(\mathrm{gm} / \mathrm{cm})\end{array}$ & $\begin{array}{l}\mathrm{DNA} / \mathrm{cm} \\
(\mathrm{mg} / \mathrm{cm})\end{array}$ & $\begin{array}{l}\text { Protein/cm } \\
(\mathrm{mg} / \mathrm{cm})\end{array}$ & $\begin{array}{c}\text { Lactase } / \mathrm{cm} \\
(\mathrm{mU} / \mathrm{cm})\end{array}$ & $\begin{array}{c}\text { Sucrase } / \mathrm{cm} \\
(\mathrm{mU} / \mathrm{cm})\end{array}$ & $\begin{array}{l}\mathrm{AOP} / \mathrm{cm} \\
(\mathrm{mU} / \mathrm{cm})\end{array}$ \\
\hline Dc & 6 & $0.08 \pm 0.01^{\mathrm{a}}$ & $0.56 \pm 0.03^{\mathrm{a}}$ & $3.7 \pm 0.2^{\mathrm{a}}$ & $32 \pm 4^{\mathrm{a}}$ & $77 \pm 12^{a}$ & $159 \pm 19^{\mathrm{a}}$ \\
\hline Dr & 6 & $0.15 \pm 0.01^{\mathrm{b}}$ & $0.83 \pm 0.06^{\mathrm{b}}$ & $10.2 \pm 1.4^{\mathrm{b}}$ & $202 \pm 45^{b}$ & $250 \pm 35^{b}$ & $434 \pm 40^{\mathrm{b}}$ \\
\hline $\mathrm{dc}$ & $6 *$ & $0.06 \pm 0.01^{\mathrm{a}}$ & $0.36 \pm 0.02^{\mathrm{c}}$ & $3.1 \pm 0.4^{\mathrm{a}}$ & $150 \pm 17^{\mathrm{c}}$ & $339 \pm 50^{\mathrm{b}}$ & $180 \pm 14^{\mathrm{a}}$ \\
\hline $\mathrm{dr}$ & 6 & $0.09 \pm 0.01^{\mathrm{a}}$ & $0.52 \pm 0.02^{\mathrm{a}}$ & $4.2 \pm 0.1^{\mathrm{a}}$ & $82 \pm 15^{\mathrm{d}}$ & $91 \pm 11^{\mathrm{a}}$ & $215 \pm 32^{\mathrm{a}}$ \\
\hline
\end{tabular}

Data presented as mean \pm SEM. For each parameter, different superscripts indicate significant differences at $p<0.05$ (ANOVA).

* Data from de and $\mathbf{d s}$ animals were grouped together as no significant differences existed between these groups.

\section{VILLUS HEIGHT}

PRE-ANASTOMOTIC

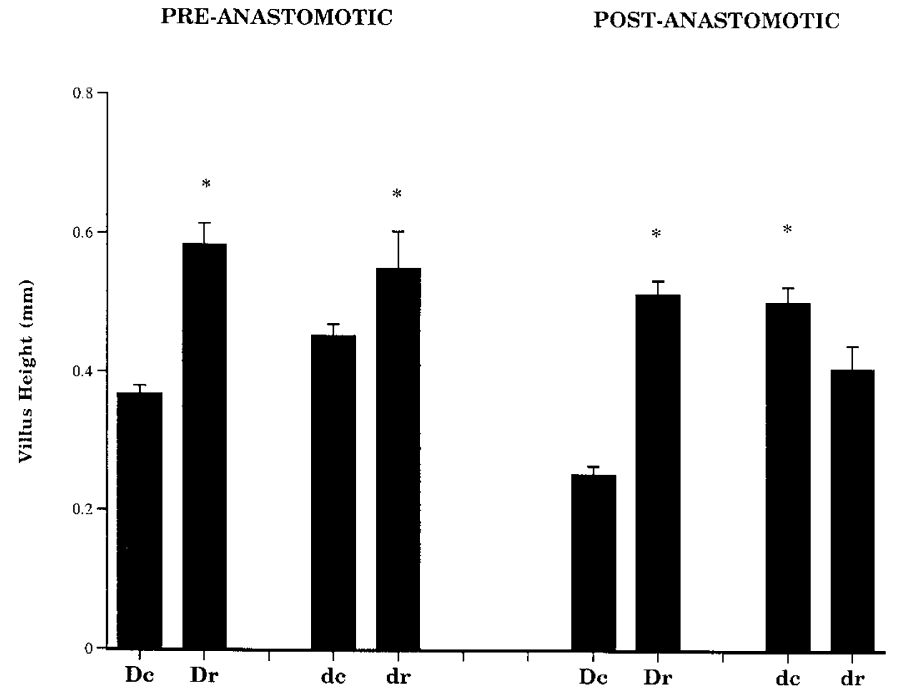

Animal Groups
Figure 2. Villus height in the pre- and postanastomotic segments of GHsufficient and GH-deficient rats. Measurements were made under blinded conditions and are presented in millimeters. *For a given region, the measurements are significantly less $(p<0.05)$ by ANOVA.

there were significant increases in the villus height in both the pre- and postanatomotic segment. In contrast, in GH deficiency, the villus height of the preanastomotic segment also increased in response to intestinal resection, whereas the villi of the postanastomotic segment of GH-deficient animals did not and were significantly shorter.

Digestive hydrolase parameters. The catalytic activities of the key digestive hydrolases, lactase, sucrase, and aminooligopeptidase were measured and the results are given in Figures 3 and 4. In the preanastomotic segment (Fig. 3), no differences in enzyme specific activities are noted in GH-sufficient animals, but lactase and sucrase were significantly higher than control in GH-deficiency. No differences were noted in AOP activity levels. Total enzyme activities (expressed as $\mathrm{mU} / \mathrm{cm}$ intestine) were significantly higher in intestines of $\mathrm{GH}$ sufficient animals, whereas no differences were noted in GHdeficient animals (Table 2).

Similar findings were noted in the postanastomotic segment. As seen in Figure 4, lactase- and sucrase-specific activities

\section{LACTASE}

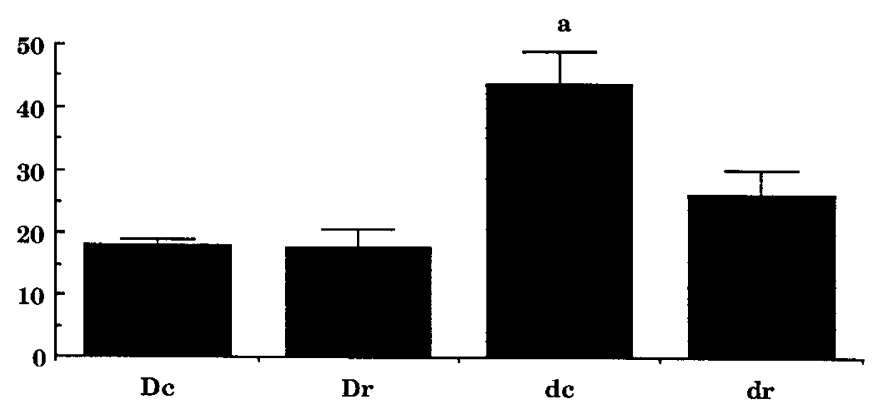

SUCRASE

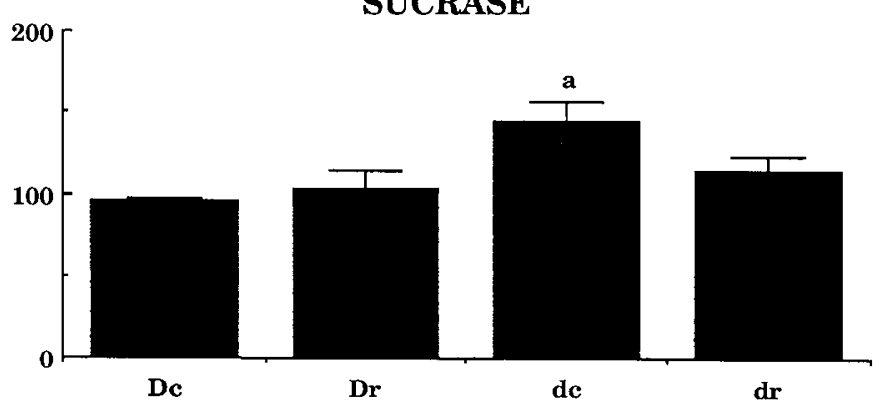

AMINOOLIGOPEPTIDASE

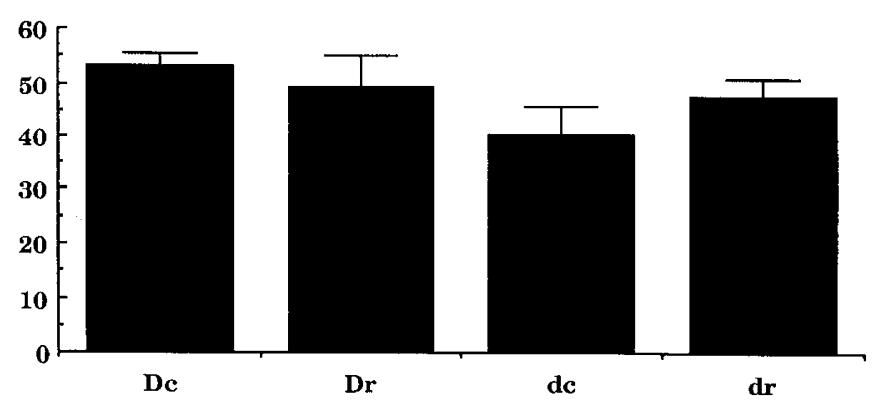

Figure 3. Digestive hydrolase-specific activities in the preanastomotic (jejunal) segment. Specific activities are expressed as $\mathrm{mU} / \mathrm{mg}$ protein. $n=6$ for all groups. a indicates significant difference from all other groups at $p<0.05$ by ANOVA.

were no different in GH-sufficient animals whereas AOP levels were significantly higher in control animals. Lactase and sucrase were higher in GH-deficiency whereas aminooligopeptidase activities were unchanged. As shown in Table 3, total activities of the hydrolases were all markedly elevated in GH-sufficiency, whereas in GH-deficiency, total activities were either unchanged (AOP) or lower than control (lactase, sucrase). 


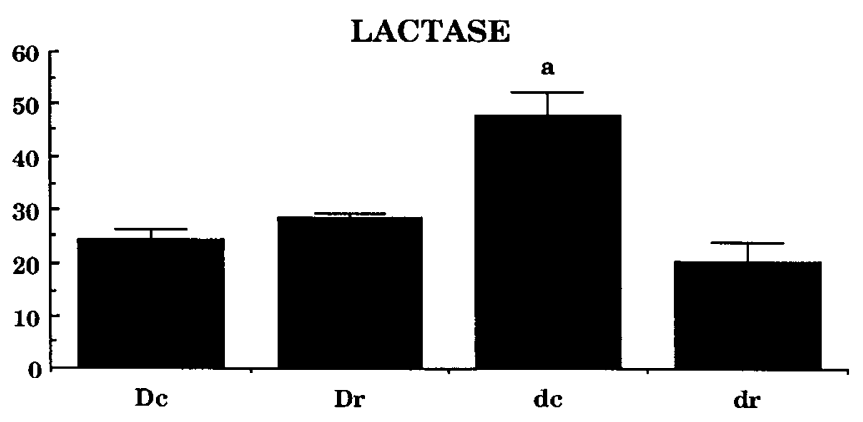

SUCRASE

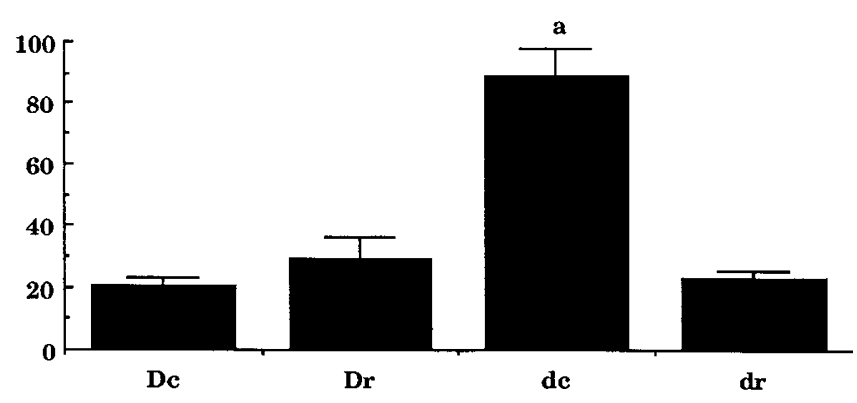

AMINO-OLIGOPEPTIDASE

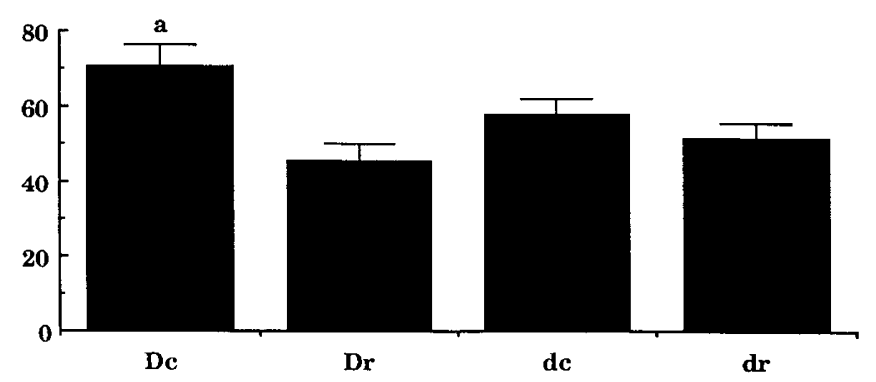

Figure 4. Digestive hydrolase specific activities in the postanastomotic (ileal) segment. Specific activities are expressed as $\mathrm{mU} / \mathrm{mg}$ protein. $n=6$ for all groups. a indicates significant difference from all other groups at $p<0.05$ by ANOVA.

Analysis of the subunit structure of the hydrolases was done by SDS-PAGE. As seen in Figure 5, the subunit structure of lactase is identical in GH-sufficiency and GH-deficiency in the preanastomotic segment. However, in the postanastomotic segment of GH-deficient animals, the major $130 \mathrm{kDa}$ lactase band is missing and two lower molecular weight lactase subunits appear, suggesting altered processing of lactase. Similar findings were noted on analysis of AOP by SDS-PAGE. The subunit structure is identical in the preanastomotic segments of both GH-sufficient and GH-deficient animals, whereas the major $140 \mathrm{kDa}$ band migrates more slowly in the postanastomotic segment of GH-deficient animals (Fig. 7). This suggests that the processing of the AOP protein is altered in $\mathrm{GH}-$ deficiency. No differences in sucrase subunits were noted (Fig. 6).

Serum levels of IGF-I. As a further confirmation of GH status, serum IGF-I levels, a peptide known to be GH dependent, were determined on a subset of three animals from each experimental group. The results were $\mathbf{D r}=1186 \pm 262 \mathrm{ng}$
IGF-I $/ \mathrm{mL}$ serum, $\mathbf{D c}=1277 \pm 227 \mathrm{ng}$ IGF-I $/ \mathrm{mL}$ serum, $\mathbf{d r}=$ $18 \pm 4 \mathrm{ng}$ IGF-I $/ \mathrm{mL}$ serum, dc $=29.5 \pm 6 \mathrm{ng}$ IGF-I $/ \mathrm{mL}$ serum. As is apparent, GH-deficient animals had exceedingly low levels of IGF-I, as expected.

\section{DISCUSSION}

Although previous studies have suggested a role for $\mathrm{GH}$ in regulation of intestinal adaptation to resection $(12,28)$, the specific role of GH has not yet been elucidated. To study the role of $\mathrm{GH}$, a resection of $60 \%$ of the mid-small bowel was performed on rats congenitally deficient in GH. The mechanism of GH deficiency in this rat model has been extensively investigated and has been established as an isolated deficiency of GH $(27,29)$. This model therefore allows investigation of the specific role of $\mathrm{GH}$ in regulation of the augmentation of growth of the intestinal remnant that characterizes adaptation to surgical resection.

Massive resection of the small intestine results in profound hyperplasia of the mucosal epithelium, producing markedly increased digestive and absorptive function of the remnant intestine $(2-4,30-33)$. Features of this classic response are exhibited by our group of GH-sufficient animals undergoing intestinal resection (Dr). As seen in Table 2 and Table 3, both the pre- and postanastomotic segments of Dr intestine showed increased segmental weight, DNA content, protein content, and villus height compared with analogous intestinal segments in control animals not undergoing intestinal resection (Dc). In addition, segmental enzyme activities are also significantly higher in Dr as opposed to Dc. Because enzyme specific activities were generally no different in Dr and Dc (Figs. 3 and 4), the increases in enzyme content are most likely due to increased numbers of epithelial cells containing a normal concentration of enzyme, as has been proposed previously $(1,34)$.

A different pattern of response is seen in the intestines of GH-deficient animals. Although increases in segmental weight and DNA content are noted generally, no significant increases in segmental protein content occurred, including lack of increase or actual decrease in segmental enzyme-protein content. These data suggest that GH is not required for mucosal cell proliferation and hyperplasia after intestinal resection but is required for the normal expression of the profound accumulation of mucosal protein and digestive hydrolases that normally occurs in response to intestinal resection.

The metabolism of the digestive hydrolases investigated in this study was clearly different in GH-deficient animals after intestinal resection. Instead of the well-described increases in total intestinal digestive enzyme content that is an essential feature of adaptation to surgical resection, total intestinal digestive enzyme levels were either no different from control (preanastomotic segment) or actually lower than control (postanastomotic segment) in GH deficiency after resection (Tables 2 and 3). In addition, the specific activities for lactase and sucrase were reduced in both segments in GH-deficient animals after resection to levels similar to those found in $\mathrm{GH}$ normal animals. (Figs. 3 and 4). The mechanism for the reduction in lactase- and sucrase-specific activities after intes- 


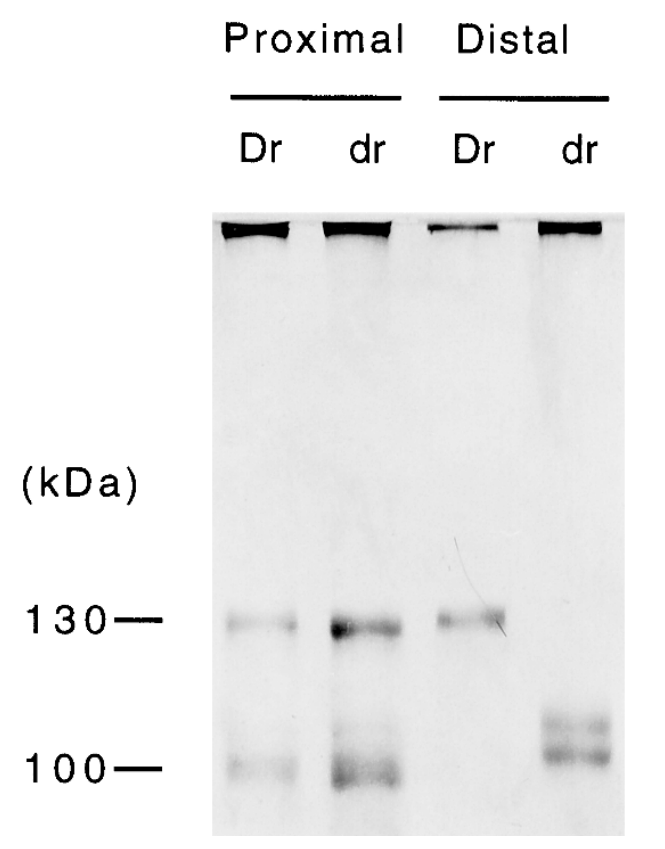

Figure 5. SDS-PAGE analysis of lactase. Total mucosal homogenates were solubilized with Triton and the supernatants analyzed by SDS-PAGE. Lactase was immunoprecipitated using monospecific, polyclonal antibody. Dr, GHnormal animals undergoing surgical resection of $60 \%$ of the small intestine; $\mathbf{d r}$, GH-deficient animals undergoing surgical resection of $60 \%$ of the small intestine; proximal, preanastomotic segment; distal, postanastomotic segment. Molecular mass $(\mathrm{kDa})$ indicators are given on the left-hand margin.

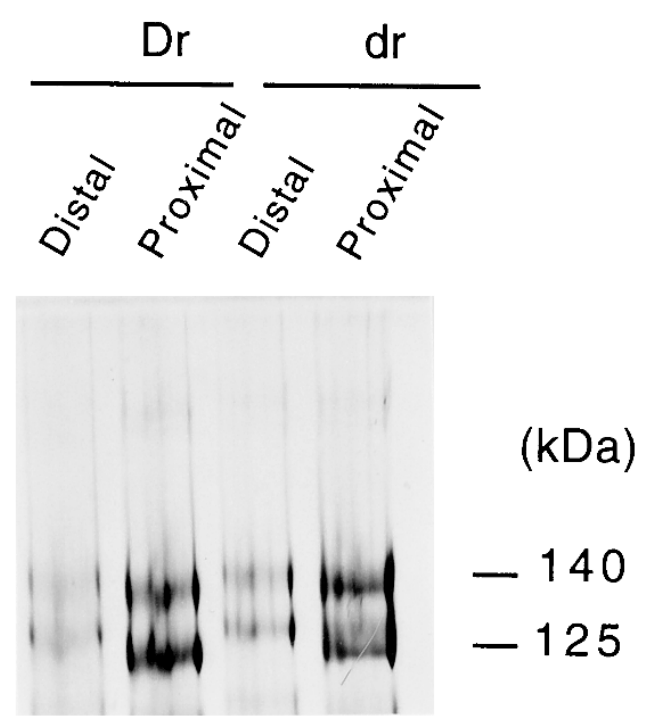

Figure 6. SDS-PAGE analysis of sucrase. Total mucosal homogenates were solubilized with Triton and the supernatants analyzed by SDS-PAGE. Sucrase was immunoprecipitated using monospecific, polyclonal antibody. Dr, GHnormal animals undergoing surgical resection of $60 \%$ of the small intestine; $\mathbf{d r}$, GH-deficient animals undergoing surgical resection of $60 \%$ of the small intestine; proximal, preanastomotic segment; distal, postanastomotic segment. Molecular mass $(\mathrm{kDa})$ indicators are given on the right-hand margin.

tinal resection in GH deficiency is unclear. Because no differences in dietary intake were found (Table 1), these lower enzyme activities cannot be ascribed to lack of luminal nutrients. Baseline specific activities of lactase and sucrase in transected (control) GH deficient small bowel are elevated relative to levels found in resected GH-deficient intestine as

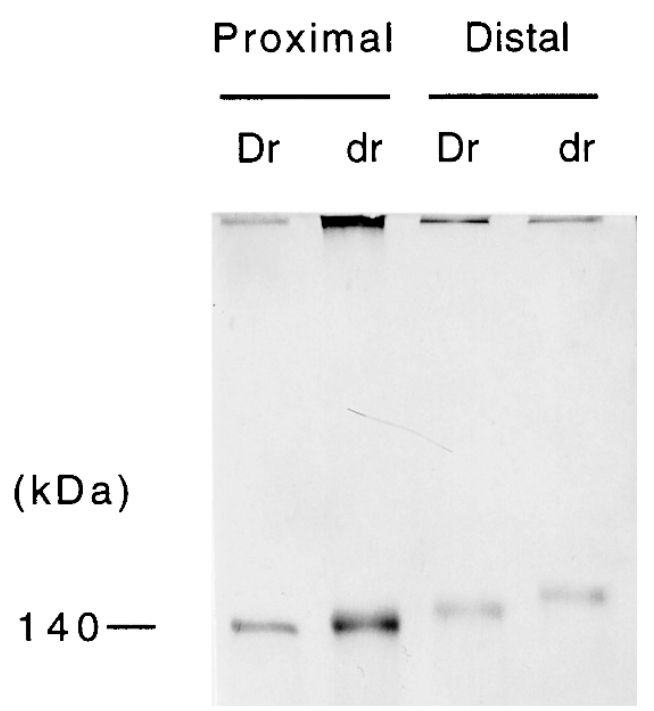

Figure 7. SDS-PAGE analysis of aminooligopeptidase. Total mucosal homogenates were solubilized with Triton and the supernatants analyzed by SDS-PAGE. Aminooligopeptidase was immunoprecipitated using monospecific, polyclonal antibody. Dr, GH-normal animals undergoing surgical resection of $60 \%$ of the small intestine; dr, GH-deficient animals undergoing surgical resection of $60 \%$ of the small intestine; proximal, preanastomotic segment; distal, postanastomotic segment. Molecular mass (kDa) indicators are given on the left-hand margin.

well as those levels found in GH normal intestine (Figs. 3 and 4). The etiology of this finding itself is not clear, but may reflect the relatively lower intestinal protein content of the GH deficient bowel (Tables 2 and 3). We have previously suggested that decreased intestinal protein may be a distinguishing feature in GH deficiency (15). Indeed, increased levels of intestinal protein are found in mice overexpressing GH (7). As enzyme-specific activities are calculated by dividing enzyme catalytic activities by intestinal protein levels, lower levels of intestinal protein will result in elevated specific activity levels. Other possibilities for this finding include alterations in cell lifespan, increased rates of enzyme synthesis, or decreased rates of enzyme degradation, but these were not directly examined in this study. To investigate possible mechanisms for the reductions in enzyme-specific activities in GH-deficient animals after intestinal resection, analysis of subunit structure of the enzyme-protein was done by SDS-PAGE. No differences in migration of enzyme subunits were noted in the preanastomotic segments of GH-deficient animals, but obvious differences were noted in the distal segments for AOP and lactase. In GH-deficiency, the AOP band clearly migrates more slowly than in GH-sufficient animals. Although the mechanism of this difference is unclear, it is possible that this difference reflects alterations in glycosylation. For AOP, we have shown that the proximal and distal differences in migration of AOP subunits were due to regional differences in glycosylation, as removal of the carbohydrate sidechains by endoglycosidase treatment resulted in AOP enzyme-protein bands that no longer differed in migration (24). Striking differences in lactase subunit structure were noted in the distal intestinal segment in GH deficiency. The absence of the normally present $130 \mathrm{kDa}$ form and the appearance of a lower molecular weight doublet indicates that 
Table 2. Parameters of response of the preanastomotic intestinal segment

\begin{tabular}{|c|c|c|c|c|c|c|c|}
\hline $\begin{array}{l}\text { Animal } \\
\text { group }\end{array}$ & $n$ & $\begin{array}{l}\text { Weight/length } \\
(\mathrm{gm} / \mathrm{cm})\end{array}$ & $\begin{array}{l}\mathrm{DNA} / \mathrm{cm} \\
(\mathrm{mg} / \mathrm{cm})\end{array}$ & $\begin{array}{l}\text { Protein/cm } \\
(\mathrm{mg} / \mathrm{cm})\end{array}$ & $\begin{array}{c}\text { Lactase/cm } \\
(\mathrm{mU} / \mathrm{cm})\end{array}$ & $\begin{array}{l}\text { Sucrase } / \mathrm{cm} \\
(\mathrm{mU} / \mathrm{cm})\end{array}$ & $\begin{array}{l}\mathrm{AOP} / \mathrm{cm} \\
(\mathrm{mU} / \mathrm{cm})\end{array}$ \\
\hline Dc & 6 & $0.09 \pm 0.01^{\mathrm{a}}$ & $0.61 \pm 0.04^{\mathrm{a}}$ & $5.1 \pm 0.3^{\mathrm{a}}$ & $95 \pm 10^{\mathrm{a}}$ & $490 \pm 37^{\mathrm{a}}$ & $177 \pm 31^{\mathrm{a}}$ \\
\hline $\mathrm{Dr}$ & 6 & $0.23 \pm 0.04^{\mathrm{b}}$ & $1.20 \pm 0.19^{\mathrm{b}}$ & $12.7 \pm 2.2^{\mathrm{b}}$ & $220 \pm 44^{b}$ & $1228 \pm 152^{\mathrm{b}}$ & $586 \pm 74^{\mathrm{b}}$ \\
\hline $\mathrm{dr}$ & 6 & $0.14 \pm 0.01^{\mathrm{c}}$ & $0.84 \pm 0.11^{\mathrm{d}}$ & $5.1 \pm 0.4^{\mathrm{a}}$ & $134 \pm 20^{\mathrm{a}}$ & $579 \pm 51^{\mathrm{a}}$ & $243 \pm 23^{\mathrm{a}}$ \\
\hline
\end{tabular}

Data presented as mean \pm SEM. For each parameter, different superscripts indicate significant differences at $p<0.05$ (ANOVA).

* Data from de and $\mathbf{d s}$ animals were grouped together as no significant differences existed between these groups.

the processing of the lactase enzyme-protein was dramatically altered in absence of GH. These data indicate that GH is required for the normal adaptive increases in digestive hydrolases after intestinal resection. In absence of GH, not only is there a lack of increase in digestive enzyme content, but alterations in lactase and AOP enzyme structure are produced. Whether these changes in enzyme structure result in alterations in enzyme metabolism, such as increased rates of degradation, is unclear. Other potential mechanisms for alterations in enzyme-specific activities to be considered include alterations in epithelial cell lifespan. Epithelial cell lifespan has been shown to be decreased due presumably to more rapid cellular turnover after intestinal resection (1). This may result in decreased enzyme activities because of accelerated enzyme loss (23).

The mechanisms by which GH acts on intestinal tissues to regulate protein synthesis in general and digestive hydrolase metabolism in particular are not known. GH is a potent anabolic hormone that stimulates nitrogen retention and accumulation of other nutrients essential for growth (16). As GH may stimulate an increase in dietary intake (12), it is possible that GH deficiency might result in diminished nutrient intake and hence adversely affect intestinal adaptation, which is known to require enteral nutrients (1). As shown in Table 1, however, all groups of GH-deficient animals had equivalent dietary intakes to GH-normal animals, in spite of slow rates of growth (Fig. 1). Hence the alterations in the adaptive response to intestinal resection observed in this study are not due to diminished dietary intake in this animal model. Alternatively, the lack of GH could have resulted in lack of substrate for protein synthesis in GH-dependent tissues. It has been shown that a short course of supplemental GH therapy enhances amino acid uptake in the human small bowel (35). In absence of GH, it is therefore possible that amino acid transport in the small intestine is diminished, resulting in diminished levels of protein synthesis in intestinal tissues. Finally, it is also possible that GH deficiency results in alterations in protein synthesis or rates of protein turnover such that abnormal and possibly inactive proteins are synthesized or rates of protein turnover are increased to make amino acid substrates more available for local or systemic sites.

In summary, we have investigated the role of GH in the adaptive response to massive small intestinal resection in rats with isolated GH deficiency. In GH deficiency, the marked hyperplasia of the mucosal epithelium, characteristically seen in the adaptive response, was preserved in both the proximal (jejunal) and distal (ileal) intestinal remnant, indicating that this feature of intestinal adaptation to resection is not GH dependent. However, GH deficiency resulted in lack of accu- mulation of intestinal protein in both segments, including lack of accumulation of digestive hydrolases. In addition, GH deficiency resulted in alterations in processing of digestive hydrolases of the distal intestine, indicating that $\mathrm{GH}$ has regionspecific effects on the small intestine. In the aggregate, these data indicate that specific components of the adaptive response to massive small intestinal resection require $\mathrm{GH}$ for their normal expression, but other components do not. Because of these findings, studies investigating the effect of exogenous GH in intestinal resection would very likely produce no effect on intestinal hyperplasia, as this is not a GH-dependent process. However, there may be an effect seen on the digestive hydrolases of the distal intestinal remnant, as we have demonstrated alterations in digestive enzyme activity and structure in this region of the intestine in GH-deficient animals undergoing surgical resection. Indeed, the results of a recent report appear to support these predictions in that the authors report the infusion of GH in rats undergoing massive small bowel resection did not stimulate hyperplasia but did stimulate sucrase and maltase levels in the ileal remnant (10) .

\section{REFERENCES}

1. Williamson R, Chir M 1978 Intestinal adaptation. N Engl J Med 298:1393-1402, $1444-1450$

2. Dowling RE, Booth CC 1967 Structural and functional changes following small intestinal resection in the rat. Clin Sci 32:139-149

3. Dowling RH, Gleeson MH 1973 Cell turnover following small bowel resection and by-pass. Digestion 8:176-190

4. Dowling RH 1982 Small bowel adaptation and its regulation. Scand J Gastroenterol 17(suppl 74):53-74

5. Castillo RO, Glasscock GF, Noren KM, Reisenauer AM 1991 Pituitary regulation of postnatal small intestinal ontogeny in the rat: differential regulation of digestive hydrolase maturation by thyroxine and growth hormone. Comp Biochem Physiol C Pharmacol Toxicol 129:1417-1423

6. Lobie PE, Breipohl S, Water MJ 1990 Growth hormone receptor expression in the rat gastrointestinal tract. Comp Biochem Physiol C Pharmacol Toxicol 126:299-306

7. Ulshen MH, Dowling RH, Fuller CR, Zimmerman EM, Lund PK 1993 Enhanced growth of small bowel in transgenic mice overexpressing bovine growth hormone. Gastroenterol 104:973-980

8. Lemmey AB, Martin AA, Read LC, Thomas FM, Owens PC, Ballard FJ 1991 IGF-I and the truncated analogue des-(1-3)-IGF-I enhance growth in rats after gut resection. Am J Physiol 260:E213-E219

9. Vanderhoof JA, McCusker RH, Clark R, Mohammadpour H, Blackwood DJ, Harty RF, Park JHY 1992 Truncated and native insulin-like growth factor I enhance mucosal adaptation after jejunoileal resection. Gastroenterology 102:1949-1956

10. Park J, Vanderhoof J 1996 Growth hormone did not enhance mucosal hyperplasia after small bowel resection. Scand J Gastroenterol 31:349-354

11. Benhamou PH, Canarelli JP, Leroy C, DeBoissieu D, Dupont C 1994 Stimulation by recombinant human growth hormone of growth and development of remaining bowel after subtotal ileojejunectomy in rats. J Pediatr Gastroenterol Nutr 18:446-452

12. Schulman DI, Hu CS, Duckett G, Lavelle-Grey M 1992 Effects of short-term growth hormone therapy in rats undergoing $75 \%$ small intestinal resection. J Pediatr Gastroenterol Nutr 14:3-11

13. Takeuchi T, Suzuki H, Sakurai S, Nogami H, Okuma S, Ishikawa H 1990 Molecular mechanism of growth hormone $(\mathrm{GH})$ deficiency in the spontaneous dwarf rat: detection of abnormal splicing of $\mathrm{GH}$ messenger ribonucleic acid by polymerase chain reaction. Comp Biochem Physiol C Pharmacol Toxicol 126:31-38

14. Nogami H, Takeuchi T, Suzuki K, Okuma S, Ishikawa H 1989 Studies on prolactin and growth hormone gene expression in the pituitary gland of spontaneous dwarf rats. Comp Biochem Physiol C Pharmacol Toxicol 125:964-970 
15. Durant M, Gargosky S, Dahlstrom K, Hellman B, Castillo R 1996 Regulation of postnatal intestinal maturation by growth hormone: studies in rats with isolated growth hormone deficiency. Pediatr Res 40:88-93

16. Gargosky SE, Tapanainen P, Rosenfeld RG 1994 Administration of growth hormone (GH) but not insulin-like growth factor-I (IGF-I), by continuous infusion can induce the formation of the 150-kilodalton IGF-binding protein-3 complex in GH-deficient rats. Comp Biochem Physiol C Pharmacol Toxicol 134:2267-2276

17. Underwood LE, Wyk JJV 1992 Normal and Aberrant Growth. WB Saunders, Philadelphia, pp 1075-1138

18. Dahlqvist A 1964 Method for assay of intestinal disaccharidases. Ann Biochem $7: 18-25$

19. Tsuboi KK, Kwong LK, Burrill PH, Sunshine P 1979 Sugar hydrolases and thei arrangement on the rat intestinal microvillus membrane. J Membr Biol 50:101-122

20. Wojnarowska F, Gray GM 1975 Intestinal surface peptide hydrolases: identification and characterization of three enzymes from rat brush border. Biochimica Biophysica Acta 403:147-160

21. Bradford MM 1972 A rapid and sensitive method for the quantitation of microgram quantities of protein utilizing the principle of protein-dye binding. Ann Biochem $72: 248-254$

22. Labarca C, Paigen K 1980 A simple, rapid and sensitive DNA assay procedure. Ann Biochem 102:344-352

23. Castillo RO, Reisenauer AM, Kwong LK, Tsuboi KK, Quan R, Gray GM 1990 Intestinal lactase in the neonatal rat: maturational changes in intracellular processing and brush border degradation. J Biol Chem 265:15889-15893

24. Reisenauer AM, Lee EA, Castillo RO 1992 Ontogeny of membrane and soluble aminooligopeptidases in rat intestine. Am J Physiol 262:G178-G184
25. Tsuboi KK, Schwartz SM, Burrill PH, Kwong LK, Sunshine P 1979 Sugar hydrolases of the infant rat intestine and their arrangement on the brush border membrane. Biochimica Biophysica Acta 554:234-248

26. Laemmli UK 1970 Cleavage of structural proteins during the assembly of the head of bacteriophage T4. Nature 227:680-685

27. Okuma S, Kawashima S 1980 Spontaneous dwarf rat. Exp Animal Sci 29:301

28. Hart MH, Phares CK, Erdnman SH, Grandjean CJ, Park JHY, Vanderhoof JA 1987 Augmentation of postresection mucosal hyperplasia by Plerocercoid growth factor (PCF) analog of human growth hormone. Dig Dis Sci 32:1275-1280

29. Park JHY, Vanderhoof JA, Blackwood D, MacDonald RG 1990 Characterization of type I and type II insulin-like growth factor receptors in an intestinal epithelial cell line. Comp Biochem Physiol C Pharmacol Toxicol 126:2998-3005

30. Weser E, Hernandez MH 1971 Studies of small bowel adaptation after intestinal resection in the rat. Gastroenterology 60:69-75

31. Vanderhoof JA, Burkley KT, Antonson DL 1983 Potential for mucosal adaptation following massive small bowel resection in 3-week versus 8-week old rats. J Pediatr Gastroenterol Nutr 2:672-676

32. Johnson LR 1988 Regulation of gastrointestinal mucosal growth. Physiol Rey 68:456-502

33. Booth CC, Evans KT, Menzies T, Street DF 1959 Intestinal hypertrophy following partial resection of the small bowel in the rat. Br J Surg 46:403-410

34. Hartman GE, Castillo RO, Kwong LK, Sunshine P, Tsuboi KK 1988 Maturational patterns of carbohydrases in the ileal remnant of rats after jejunectomy at infancy. Am J Clin Nutr 47:868-874

35. Inoue Y, Copeland E, Souba W 1994 Growth hormone enhances amino acid uptake by the human small intestine. Ann Surg 219:715-724 